\title{
FAKTOR-FAKTOR YANG MEMPENGARUHI PRODUKTIVITAS TENAGA KERJA PEMANEN KELAPA SAWIT DI PT. PERKEBUNAN NUSANTARA III (PERSERO) MEDAN
}

\author{
Tennisya Febriyanti Suardi ${ }^{1}$, Trisna Insan Noor ${ }^{2}$, Iwan Setiawan ${ }^{2}$ \\ ${ }^{1)}$ Mahasiswa Program Studi Ilmu Ekonomi Pertanian Pascasarjana Fakultas Pertanian Universitas \\ Padjadjaran \\ ${ }^{2}$ Dosen Program Studi Ilmu Ekonomi Pertanian Pascasarjana Fakultas Pertanian Universitas \\ Padjadjaran. Jl. Raya Bandung-Sumedang KM.21, Jatinangor 40363;
}

\begin{abstract}
Abstrak
Sektor perkebunan kelapa sawit memiliki nilai ekonomi tinggi sebagai penghasil minyak nabati yang paling banyak digunakan oleh masyarakat. Di perusahaan perkebunan kelapa sawit, aspek tenaga kerja langsung yang terlibat dalam proses produksi adalah pemanen kelapa sawit. Ini membutuhkan peningkatan produktivitas pemanen kelapa sawit untuk menghasilkan tandan buah segar berkualitas yang sesuai dengan tingkat pabrik kelapa sawit. Penelitian ini bertujuan untuk menganalisis menentukan produktivitas tenaga kerja pemanen kelapa sawit dan faktor-faktor yang mempengaruhinya serta pengaruh produktivitas panen terhadap kualitas tandan buah segar kelapa sawit. Metode penelitian yang digunakan adalah deskriptif kuantitatif dengan jumlah responden sebanyak 82 orang yang berprofesi sebagai pemanen kelapa sawit. Metode analisis menggunakan analisis deskriptif dan analisis PLS (Partial Least Square). Hasil penelitian menunjukkan bahwa produktivitas pemanen kelapa sawit berada dalam kategori sedang di mana ia bisa mendapatkan sebanyak 1700-2300 kilogram hasil per hari kerja. Faktor internal dan eksternal berpengaruh signifikan terhadap produktivitas pemanen. Faktor internal terbesar adalah motivasi kerja, sedangkan faktor eksternal terbesar adalah peluang untuk mencapainya. Kualitas tandan buah segar kelapa sawit di PT. Perkebunan Nusantara III (Persero) Medan dipengaruhi oleh produktivitas pemanen kelapa sawit.
\end{abstract}

Kata kunci: produktivitas, kualitas, pemanen, kelapa sawit

\begin{abstract}
The oil palm plantation sector has a high economic value as a producer of vegetable oil which is most widely used by the community. In an oil palm plantation company, the direct labor aspect involved in the production process is oil palm harvesters. This requires an increase in the productivity of oil palm harvesters to produce quality fresh fruit bunches that are in accordance with the grade of the palm oil mill. This study aims to analyze the determine labor productivity of oil palm harvesters and the factors that influence them and the effect of harvesting productivity on the quality of oil palm fresh fruit bunches. The research method used was descriptive quantitative with the number of respondents as many as 82 people who work as oil palm harvesters. The method of analysis uses descriptive analysis and PLS (Partial Least Square) analysis. The results of the study show that the productivity of oil palm harvesters was in the medium category where it can get as much as 1700-2300 kilograms of yield per working day. Internal and external factors have a significant effect on the productivity of harvesters. The biggest internal factor is work motivation, while the biggest external factor is the opportunity to achieve. The quality of palm oil fresh fruit bunches at PT. Perkebunan Nusantara III (Persero) Medan was influenced by the productivity of oil palm harvesters.
\end{abstract}

Keywords: productivity, quality, harvesters, oil palm 


\section{Pendahuluan}

Kelapa sawit merupakan tanaman yang banyak dibudidayakan di Indonesia dengan sistem perkebunan. Luas perkebunan sawit terus di tingkatkan, karena memiliki nilai ekonomi yang tinggi dan merupakan penghasil minyak nabati yang paling banyak digunakan oleh masyarakat luas, baik di Indonesia maupun Dunia. Badan Pusat Statistik (2017) melaporkan bahwa luas perkebunan sawit di Indonesia mencapai 14,03 juta hektar yang tersebar di seluruh pulau, dengan konsentrasi utama di pulau Sumatera, Kalimantan, Sulawesi dan Papua. Dari luas tersebut dihasilkan sekitar 25.034 ton minyak sawit (CPO) dan 5.018 ton inti sawit (kernel).

Perkebunan sawit ada yang dimiliki dan dikelola oleh negara, swasta dan perkebunan rakyat. Secara umum, pihak swasta menguasai lebih dari separuh $(51,62 \%)$ dari total luas perkebunan kelapa sawit di Indonesia, perkebunan rakyat sekitar $41,55 \%$ dan perkebunan negara (BUMN/PTPN) sekitar 6,83\%. Peningkatan kualitas pengelolaan perkebunan berperan penting dalam perluasan areal dan optimalisasi pemanfaatan hasil kelapa sawit di Indonesia. Menurut Afifah (2016), sumber daya manusia yang berketerampilan khusus sangat diperlukan perusahaan dalam peningkatan kualitas pengelolaan perkebunan. Harapannya, bukan hanya akan diperoleh hasil yang terbaik, tetapi juga terkait dengan upaya mewujudkan keberlanjutan (sustainability).

PT. Perkebunan Nusantara III (Persero) Medan merupakan salah satu perkebunan kelapa sawit negara yang memegang peranan penting dalam agribisnis kelapa sawit di Indonesia. Upaya peningkatan kualitas pengelolaan perkebunan dilakukannya melalui optimalisasi seluruh aspek budidaya kelapa sawit, tidak terkecuali dalam kegiatan pemanenan yang menjadi salah satu penentu produktivitas kelapa sawit. Pemanenan tanaman kelapa sawit merupakan serangkaian proses yang dimulai dari pemotongan tandan buah segar dari pohon hingga pengangkutan ke pabrik (Ismail, 2015). Cara, teknik, metode dan waktu panen sangat mempengaruhi kualitas hasil panen dan berbagai produk olahan sawit.

Pemanenan kelapa sawit ditentukan oleh baik tidaknya pengelolaan tenaga kerja pemanen. Hal ini menegaskan bagaimana seharusnya perusahaan dapat mengembangkan, menggunakan, mengevaluasi memelihara tenaga kerja pemanen dalam kuantitas dan kualitas yang tepat. Produktivitas kerja pemanen perlu diketahui sebab turut menentukan bentuk kebijakan yang dapat dilakukan perusahaan. Pengelolaan tenaga kerja pemanen yang baik dapat mengurangi tingkat kesalahan panen kelapa sawit dan meningkatkan produktivitas kerjanya, sehingga kualitas dan kuantitas kelapa sawit yang dihasilkan menjadi baik dan memudahkan pencapaian tujuan perusahaan (Simamora, 2016).

Produktivitas pemanen yang tidak mencapai target standar panen merupakan salah satu masalah yang dihadapi perusahaan perkebunan di Indonesia, termasuk di PTPN III Medan. Apalagi dengan diberlakukannya tujuan pembangunan berkelanjutan (sustainable development goals/SDGs) telah memperluas standar sawit ke arah produktivitas hijau (green productivity) dan atau produktivitas ramah lingkungan (ecofriendly). Meskipun keseluruhan hasil produksi sudah mencukupi, namun secara individual belum menunjukkan produktivitas tenaga kerja yang optimal. Penelitian ini bertujuan untuk: (1) menganalisis produktivitas tenaga kerja pemanen kelapa sawit yang memenuhi standar; dan (2) menganalisis faktor-faktor yang mempengaruhi produktivutas tenaga kerja pemanen kelapa sawit. 


\section{Metodologi Penelitian}

Penelitian ini didesain secara kuantitatif dengan menggunakan metode survei dan analisis kuantitatif deskriptif. Penelitian dilakukan di PT. Perkebunan Nusantara III (Persero) Medan dengan sampel lokasi yang dipilih secara sengaja (purposive) di Unit Kebun Bukit Tujuh dan Aek Torop yang terletak di Kabupaten Labuhan Batu Selatan, Sumatera Utara. Lokasi penelitian dipilih dengan pertimbangan keduanya memiliki kualitas tandan buah segar kelapa sawit yang terbaik. Sebanyak 82 sampel dipilih secara proporsionate random sampling dari 443 populasi tenaga kerja pemanen. Data primer diperoleh dari responden melalui wawancara terstruktur dengan menggunakan alat bantu kuesioner, sedangkan data sekunder diperoleh dari perusahaan, dinas perkebunan dan BPS.

Data primer yang berhasil dikumpulkan kemudian ditabulasi, diolah dan dianalisis secara statistik deskriptif. Produktivitas tenaga kerja pemanen dianalisis dengan sistem masukan fisik perorangan per hari kerja (Nainggolan, 2012), sedangkan faktorfaktor yang mempengaruhi produktivitas tenaga kerja pemanen dianalisis dengan menggunakan PLS (Partial Least Square). Pengujian model struktural dalam PLS dilakukan dengan bantuan software SmarPLS 2.0 dengan langkah-langkah sebagai berikut: (1) Merancang model struktural (inner model); (2) Merancang model pengukuran (outer model); (3) Mengkonstruksi diagram jalur; (4) Konversi diagram jalur ke sistem persamaan; (5) Estimasi koefisien jalur, Loading dan Weight; (6) Evaluasi Goodness of Fit; dan (7) Pengujian Hipotesis.

\section{Hasil dan Pembahasan}

Hasil penelitian menunukkan mayoritas tenaga kerja pemanen kelapa sawit di PT. Perkebunan Nusantara III Persero Medan

\section{Produktivitas Tenaga Kerja Pemanen Kelapa Sawit}

Produktivitas mempunyai dua dimensi. Dimensi pertama adalah efektivitas yang mengarah kkepada pencapaian untuk kerja yang maksimal yaitu pencapaian target yang berkaitan dengan kualitas, kuantitas, dan waktu. Dimensi kedua yaitu efisinsi yang berkaitan dengan upaya membandingkan input dengan realisasi penggunaan antara hasil yang dicapai (output) dengan keseluruhan sumber daya yang digunakan (input (Jelsama, 2017).

Hasil panen yaitu diperoleh tenaga kerja pemanen kelapa sawit di PT. Perkebunan Nusantara III (Persero) Medan berbedabeda. Dimana mayoritas kurang dari target yang ditetapkan perushaan tetapi ada juga beberapa pemanen yang melebihi target sehingga dapat dikomulasikan dengan target yang tidak tercapai. Pada PT. Perkebunan Nusantara III (Persero) Medan standar yang digunakan adalah kilogram tandan buah segar yang dapat dipanen per hari kerja.

\section{Tabel 1}

Produktivitas Pemanen Sawit di PT.

Perkebunan Nusantara III (Persero) Medan

\begin{tabular}{|c|c|c|c|}
\hline $\begin{array}{l}\text { roduktivitas } \\
\text { Kategori(Kg/Hari) } \\
\end{array}$ & $\begin{array}{c}\text { Jumla } \\
\mathrm{h} \\
\text { (orang } \\
\text { ) }\end{array}$ & $\begin{array}{c}\text { Kisaran } \\
\text { (kgTBS } \\
)\end{array}$ & $\%$ \\
\hline Rendah )00-1600 & 25 & & 30,49 \\
\hline & & $1000-$ & \\
\hline Sedang $700-2300$ & 47 & 3000. & 57,32 \\
\hline Tinggi $\quad 100-3000$ & 10 & & 12,19 \\
\hline Jumlah & 82 & & $\begin{array}{l}100,0 \\
0\end{array}$ \\
\hline
\end{tabular}

Sumber: Hasil Pengolahan Data (2019)

memiliki produktivitas dalam kategori sedang yaitu dengan hasil panen per hari sebanyak 1700-2300 kilogram dengan jumlah tenaga kerja pemanen kelapa sawit 
47 orang dan persentase sebesar 57,32 persen. Sedangkan rata-rata keseluruhan produktivitas tenaga kerja pemanen kelapa sawit adalah 2044,51. Hal ini disebabkan karena perusahaan mentargetkan setiap tenaga kerja pemanen kelapa sawit dapat memanen tandan buah segar kelapa sawit sebanyak 2000 kilogram, sedangkan pada realisasinya tenaga kerja pemanen kelapa sawit tidak semuanya dapat mencapai target tersebut. Ada beberapa orang yang kurang dari target 2000 kilogram, ada yang sama dengan dan ataupun melebihi target tersebut. Hal ini nantinya akan berpengaruh terhadap penilaian kinerja masing-masing tenaga kerja pemanen kelapa sawit di PT. Perkebunan Nusantara III (Persero) Medan.

\section{Analisis Faktor-faktor yang Mempengaruhi Produktivitas Pemanen}

Untuk melihat faktor-faktor yang berpengaruh terhadap produktivitas tenaga kerja pemanen kelapa sawit di PT. Perkebunan Nusantara III (Persero) Medan dilakukan analisis Partial Least Square (PLS). Analisis ini digunakan dengan melihat skala ukur dari masing-masing indikator yang berbeda. Selain dalam multi skala, jumlah responden yang tergolong sedikit (82 responden) menjadi hambatan jika ingin dilakukan analisis dengan menggunakan analisis faktor atau Structural Equatio Model (SEM). Dengan demikian, analisis dengan menggunakan PLS tepat digunakan.

\section{Evaluasi Model Pengukuran}

Evaluasi pengukuran (outer model) Partial Least Square (PLS) adalah untuk mengetahui validitas dan reliabilitas indikator-indikator yang mengukur variabel laten. Kriteria uji validitas pada sebuah penelitian mengacu pada besaran outer loading setiap indikator terhadap variabel latennya. Evaluasi terhadap model pengukuran indikator dalam penelitian ini meliputi pemerikasaan individual item reliability, internal consistency atau composite reliability, average variance extracted, dan discriminant validity. Ketiga pengukuran pertama dikelompokan dalam convergent validity.

\section{Convergent Validity}

Convergent validity terdiri dari tiga pengujian yaitu reliability item (validitas tiap indikator), composite reability, dan average variance extracted (AVE). Convergent validity digunakan untuk mengukur seberapa besar indikator yang ada dapat menerangkan dimensi. Artinya semakin besar convergent validity maka semakin besar kemampuan dimensi tersebut dalam menerapkan variabel latennya.

\section{Reliability Item}

Item reliabilitas atau biasa kita sebut dengan validitas indikator. Pengujian terhadap reability item (validitas indikator) dapat dilihat dari nilai loading factor (standardized loading). Nilai loading faktor ini merupakan besarnya korelasi antara setiap indikator dan konstraknya. Nilai loading factor diatas 0,7 dapat dikatakan ideal, artinya bahwa indikator tersebut dapat dikatakan valid sebagai indikator untuk mengukur konstrak. Meskipun demikian, nilai standardized loading factor di atas 0,5 dapat diterima. Sedangkan nilai standardized loading factor dibawah 0,5 dapat dikeluarkan dari model (Ghozali, 2014). Berikut adalah nilai reability item yang dapat dilihat pada kolom standardized loading: 


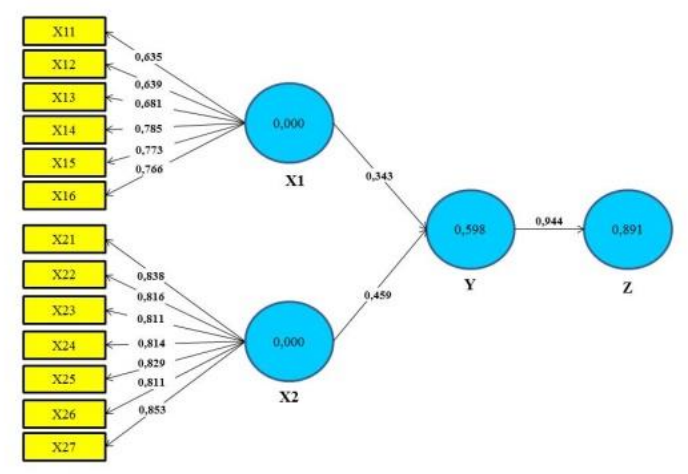

Gambar 2. Standardized Loading Factor Inner dan Outer Model

Hal ini menunjukkan bahwa nilai loading factor untuk indikator-indikator yang mengukur konstruk Faktor Internal (X1) dan Faktor Eksternal (X2) bernilai lebih dari 0,5. Tidak jauh berbeda, loading factor untuk variabel Y juga memiliki nilai yang cukup tinggi sehingga tidak perlu dikeluarkan dari model. Dengan demikian setiap indikator telah valid untuk menjelaskan masingmasing laten variabelnya, yaitu faktor internal, faktor eksternal, produktivitas, dan kualitas. Selain menunjukkan validitas item dari masing-masing indikator, loading factor juga menunjukkan besarnya kontribusi setiap indikator pada faktornya. Untuk Faktor Internal (X1) indikator yang memiliki loading paling besar adalah Motivasi Kerja (X14). Sedangkan untuk Faktor Eksternal (X2), loading factor terbesar yaitu Kesempatan Berprestasi (X27).

\section{Composite Reliability}

Statistik yang digunakan dalam composite reliability atau reabilitas konstrak adalah cronbach's alpha dan D.G rho (PCA). Nilai cronbach's alpha dan D.G rho (PCA) di atas 0,7 menunjukkan konstrak memiliki reabilitas atau keterandalan yang tinggi sebagai alat ukur. Nilai batas 0,7 keatas berarti dapat diterima dan di atas 0,8 dan 0,9 berarti sangat memuaskan (Nunnally dan
Bernstein, 1994 dalam Sofyan Yamin dan Heri Kurniawan, 2011:19).

Tabel 2

Hasil Composite Reliability

\begin{tabular}{ll}
\hline & Composite Reliability \\
\hline $\mathbf{Z}$ & 0,874 \\
$\mathbf{X 1}$ & 0,862 \\
$\mathbf{X 2}$ & 0,937 \\
$\mathbf{Y}$ & 0,856 \\
\hline
\end{tabular}

Sumber : Hasil Pengolahan Data (2019)

Berdasarkan Tabel 2 di atas menunjukkan bahwa nilai composite reliability untuk semua variabel di atas 0,7 sehingga dapat dikatakan memiliki reliabilitas atau keterandalan yang baik sebagai alat ukur. Faktor Internal (X1) sebesar 0,862 dan untuk Faktor Eksternal (X2) sebesar 0,937 dan Produktivitas (Y) sebesar 0,856 serta Kualitas (Z) sebesar 0,874.

Average Variance Extracted (AVE)

Average Variance Extracted (AVE) menggambarkan besaran variance yang mampu dijelaskan oleh item-item dibandingkan dengan varian yang disebabkan oleh error pengukuran. Standarnya adalah bila nilai AVE diatas 0,5 maka dapat dikatakan bahwa konstrak memiliki convergent validity yang baik. Artinya, variabel laten dapat menjelaskan rata-rata lebih dari setengah variance dari indikator-indikatornya.

Tabel 3

Hasil Average Variance Extracted (AVE)

\begin{tabular}{ll} 
& AVE \\
\hline $\mathbf{Z}$ & 0,874 \\
$\mathbf{X 1}$ & 0,513 \\
$\mathbf{X} 2$ & 0,680 \\
$\mathbf{Y}$ & 0,856 \\
\hline
\end{tabular}

Sumber : Hasil Pengolahan Data (2019) 
Berdasarkan Tabel 3 menunjukkan bahwa nilai AVE untuk semua variabel memiliki nilai yang berada di atas 0,5 sehingga konstrak memiliki convergent validity yang baik dimana variabel laten dapat menjelaskan rata-rata lebih dari setengah variance dari indikator-indikatornya. Dimana Faktor Internal (X1) sebesar 0,513 dan Faktor Eksternal (X2) sebesar 0,680 dan untuk Produktivitas (Y) sebesar 0,856 serta Kualitas (Z) sebesar 0,874.

\section{Discriminant Validity}

Pemeriksaan discriminant validity dari model pengukuran reflektif yang dinilai berdasarkan cross loading dan membandingkan antara nilai AVE dengan kuadrat korelasi antarkonstrak. Ukuran cross loading adalah membandingkan korelasi indikator dengan konstraknya dan konstrak dari blok lain. Discriminant validity yang baik akan mampu menjelaskan variabel indikatornya lebih tinggi dibandingkan dengan menjelaskan varian dari indikator konstrak yang lain.

Hasil menunjukkan bahwa menunjukan bahwa nilai discriminant validity atau loading factor untuk Umur (X11) adalah 0,635. Korelasi indikator Umur lebih tinggi pada Faktor Internal (X1) dibandingkan pada Faktor Eksternal (X2), yaitu sebesar 0,401; terlebih Produktivitas (Y) sebesar 0,344 dan pada Kualitas (Z) sebesar 0,397. Korelasi indikator Pendidikan (X12) lebih tinggi pada Faktor Internal (X1) $(0,639)$ dibandingkan korelasi pada Faktor Eksternal (X2) (0,383) ataupun Produktivitas (Y) $(0,281)$ dan Kualitas $(Z)(0,351)$, demikian seterusnya. Semua nilai loading factor untuk tiap variabel memiliki korelasi yang lebih tinggi dengan variabelnya dibandingkan dengan variabel lainnya. Demikian pula dengan indikator -indikator tiap variabelnya. Ini menunjukkan bahwa penempatan indikator pada tiap faktornya telah tepat.

\section{Evaluasi Model Struktural}

Ada beberapa tahap dalam mengevaluasi model struktural. Pertama adalah melihat signifikansi pengaruh antara konstrak. Hal ini dapat dilihat dari koefisien jalur (path coefficient) yang menggambarkan kekuatan hubungan antar konstrak.

\section{Path Coeffecient}

Melihat signifikansi pengaruh antara konstrak dapat dilihat dari koefisien jalur (path coefficient). Tanda dalam path coefficient harus sesuai dengan teori yang dihipotesiskan, untuk menilai signifikansi path coefficient dapat dilihat dari $\mathrm{t}$ test (critical ratio) yang diperoleh dari proses bootstrapping (resampling method). Berikut hasil pengujian $\mathrm{t}$ terhadap innes dan outer model.

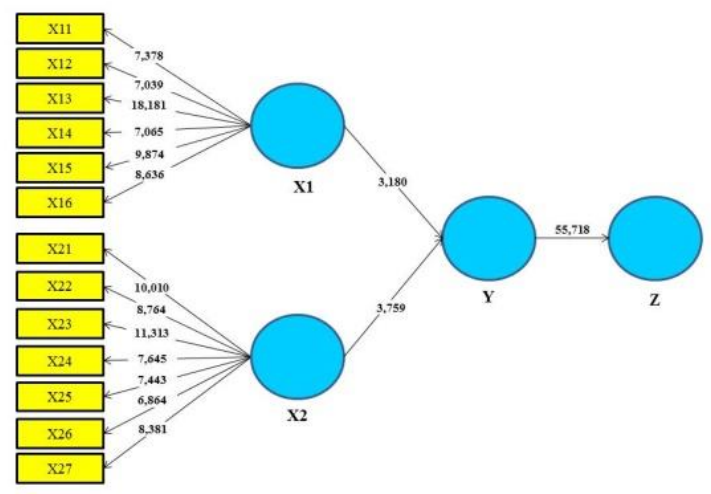

Gambar 3. T-Value Inner dan Outer Model

Uji t yang dilakukan merupakan hasil uji t dari perhitungan secara bootsttrap. Hasil uji $\mathrm{t}$ pada gambar di atas selanjutnya akan dibandingkan dengan nilai t tabel. 


\begin{tabular}{|c|c|c|c|c|c|c|}
\hline \multicolumn{7}{|c|}{$\begin{array}{c}\text { Tabel } 4 \\
\text { Hasil Path Coefficient Pengaruh } \\
\text { Langsung }\end{array}$} \\
\hline & $\begin{array}{l}\text { Orig } \\
\text { inal } \\
\text { Sam } \\
\text { ple } \\
\text { (O) }\end{array}$ & $\begin{array}{l}\text { Sam } \\
\text { ple } \\
\text { Mea } \\
\text { n } \\
(\mathrm{M})\end{array}$ & $\begin{array}{l}\text { Stand } \\
\text { ard } \\
\text { Devi } \\
\text { ation } \\
\text { (STD } \\
\text { EV) }\end{array}$ & $\begin{array}{l}\text { Stand } \\
\text { ard } \\
\text { Error } \\
\text { (STE } \\
\text { RR) }\end{array}$ & $\begin{array}{l}\mathrm{T} \\
\text { Statisti } \\
\text { cs } \\
(\mid \mathrm{O} / \mathrm{ST} \\
\mathrm{ERR} \mid)\end{array}$ & $\begin{array}{l}\mathrm{T} \\
\mathrm{Ta} \\
\text { ble }\end{array}$ \\
\hline X & 0,34 & 0,34 & 0,108 & 0,108 & 3,180 & 1,9 \\
\hline $\begin{array}{l}1 \\
-\end{array}$ & 3 & 3 & & & & 90 \\
\hline
\end{tabular}

Kriteria pengujian adalah tolak Ho jika t hitung $>\mathrm{t}$ tabel. Dari tabel $\mathrm{t}$ didapat nilai tabel untuk $\alpha=0,05$ dan $\mathrm{dk}=\mathrm{n}-2=82-2$ $=80$ sehingga didapat $\mathrm{t}$ tabel sebesar 1,990 . Dari tabel di atas, dapat dilihat bahwa :

a) Nilai t statistik untuk Faktor Internal (X1) terhadap Produktivitas (Y) sebesar 3,180. Jika dibandingkan dengan nilai $\mathrm{t}$ tabel, maka $\mathrm{t}$ hitung $(3,180)>t$ tabel $(1,990)$ sehingga Ho ditolak. Dengan demikian dapat disimpulkan terdapat pengaruh yang signifikan dari Faktor Internal (X1) terhadap Produktivitas (Y). Besarnya pengaruh Faktor Internal (X1) terhadap Produktivitas (Y) sebesar 0,343 . Koefisien jalur yang bernilai positif menunjukkan semakin baik Faktor Internal (X1) maka semakin baik pula Produktivitas (Y) tenaga kerja pemanen kelapa sawit.

b) Nilai t statistik untuk Faktor Eksternal (X2) terhadap Produktivitas (Y) sebesar 3,759. Jika dibandingkan dengan nilai $\mathrm{t}$ tabel, maka $\mathrm{t}$ hitung $(3,759)>t$ tabel $(1,990)$ sehingga Ho ditolak. Dengan demikian dapat disimpulkan terdapat pengaruh yang signifikan dari Faktor Eksternal (X2) terhadap Produktivitas (Y). Besarnya pengaruh Faktor Eksternal (X2) terhadap Produktivitas (Y) sebesar 0,459 . Koefisien jalur yang bernilai positif menunjukkan semakin baik

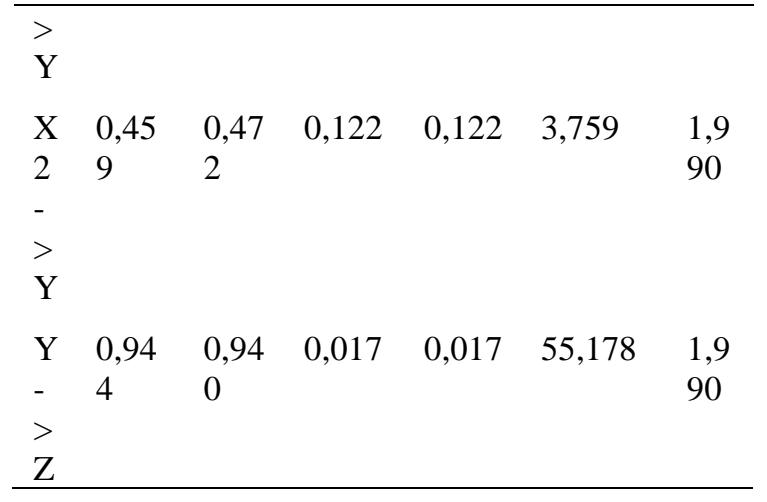

Sumber : Hasil Pengolahan Data (2019)

Faktor Eksternal (X2) maka semakin baik pula Produktivitas (Y) tenaga kerja pemanen kelapa sawit.

c) Nilai t statistic untuk Produktivitas (Y) terhadap Kualitas (Z) sebesar 55,178. Jika dibandingkan dengan nilai $t$ tabel, maka $\mathrm{t}$ hitung $(55,178)>\mathrm{t}$ tabel $(1,990)$ sehingga Ho ditolak. Dengan demikian dapat disimpulkan terdapat pengaruh yang signifikan dari Produktivitas (Y) terhadap Kualitas (Z). Besarnya pengaruh Produktivitas (Y) terhadap Kualitas (Z) sebesar 0,944 . Koefisien jalur yang bernilai positif menunjukkan semakin baik Produktivitas (Y) maka semakin baik pula Kualitas (Z) tenaga kerja pemanen kelapa sawit.

Evaluasi $R^{2}$

Berdasarkan nilai $\mathrm{R}^{2}$ diketahui bahwa Faktor Internal (X1) dan Faktor Eksternal (X2) mampu menjelaskan Produktivitas (Y) tenaga kerja pemanen kelapa sawit sebesar 0,598 (59,8\%), sedangkan sisanya 40,2\% dari konstrak lainnya. Sedangkan kontribusi Produktivitas (Y) pada Kualitas (Z) sebesar $0,891(89,1 \%)$. Kontribusi terhadap nilai $\mathrm{R}^{2}$ ini dari konstak/variabel dapat dilihat dari tabel berikut. 
Tabel 5. Hasil $R^{2}$

\begin{tabular}{ll}
\hline & R Square \\
\hline $\mathbf{Z}$ & 0,891 \\
$\mathbf{Y}$ & 0,598 \\
\hline
\end{tabular}

Sumber : Hasil Pengolahan Data (2019)

Goodness Of Fit

Untuk memvalidasi model secara keseluruhan, maka digunakan goodness of fit (GoF) yang diperkenalkan oleh Tenenhaus, et al (2004) dalam Yamin dan Heri Kurniawan (2011:21). GoF index ini merupakan ukuran tunggal yang digunakan untuk memvalidasi performa gabungan antara model pengukuran dan model structural. Nilai GoF ini diperoleh dari average communalities index dikalikan dengan nilai $\mathrm{R}^{2}$ model. Berikut adalah hasil perhitungan goodness of fit model :

Tabel 6

\section{Hasil Average Communalities Index}

\begin{tabular}{lll} 
& AVE & R Square \\
\hline $\mathbf{Z}$ & 0,874 & 0,891 \\
$\mathbf{X 1}$ & 0,513 & \\
$\mathbf{X 2}$ & 0,680 & \\
$\mathbf{Y}$ & 0,856 & 0,598 \\
Rata-rata & 0,731 & 0,744 \\
GOF & 0,738 & \\
\hline
\end{tabular}

Sumber: Hasil Pengolahan Data (2019)

Berdasarkan Tabel 6 di atas hasil rata-rata communalities adalah 0,731 Nilai ini selanjutnya dikalikan dengan $\mathrm{R}^{2}$ dan diakarkan. Hasil perhitungan menunjukan bahwa nilai GoF sebesar 0,738 lebih dari 0,36 sehingga dikategorikan sebagai GoF besar, artinya bahwa model sangat baik (memiliki kemampuan yang tinggi) dalam menjelaskan data empiris.

Pengaruh Faktor Internal dan Eksternal Terhadap Produktivitas Tenaga Kerja Pemanen Kelapa Sawit
Berdasarkan hasil analisis (Gambar 23) diketahui bahwa faktor internal berpengaruh signifikan terhadap produktivitas tenaga kerja pemanen kelapa sawit. Nilai t statistik untuk faktor internal terhadap produktivitas tenaga kerja pemanen kelapa sawit sebesar 3,180. Jika dibandingkan dengan nilai $\mathrm{t}$ tabel, maka t hitung $(3,180)>t$ tabel $(1,990)$ sehingga dapat disimpulkan terdapat pengaruh yang signifikan dari faktor internal terhadap produktivitas tenaga kerja pemanen kelapa sawit. Besarnya pengaruh faktor internal terhadap produktivitas tenaga kerja pemanen kelapa sawit sebesar 0,343. Koefisien jalur yang bernilai positif menunjukkan semakin baik faktor internal maka semakin baik pula produktivitas tenaga kerja pemanen kelapa sawit.

Faktor eksternal juga memiliki pengaruh yang signifikan terhadap produktivitas tenaga kerja pemanen kelapa sawit. Nilai $t$ statistik untuk faktor eksternal terhadap produktivitas tenaga kerja pemanen kelapa sawit sebesar 3,759. Jika dibandingkan dengan nilai $t$ tabel, maka thitung $(3,759)>$ t tabel $(1,990)$ sehingga dapat disimpulkan terdapat pengaruh yang signifikan dari faktor eksternal terhadap produktivitas tenaga kerja pemanen kelapa sawit. Besarnya pengaruh faktor eksternal terhadap produktivitas tenaga kerja pemanen kelapa sawit sebesar 0,459. Koefisien jalur yang bernilai positif menunjukkan semakin baik faktor eksternal maka semakin baik pula produktivitas tenaga kerja pemanen kelapa sawit. Hal ini sejalan dengan pendapat Simamora dkk (2016), yang menyatakan bahwa semakin besar pengaruh faktor internal dan faktoreksternal tenaga kerja pemanen kelapa sawit maka akan samhat berpengaruh terhadap produktivitas tenaga kerj pemanen itu sendiri.

\section{Pengaruh Produktivitas Tenaga Kerja Pemanen Kelapa Sawit Terhadap Kualitas Tandan Buah Segar}


Hasil pengujian hipotesis kedua menunjukkan adanya pengaruh signifikan dari produktivitas tenaga kerja pemanen kelapa sawit terhadap kualitas tandan buah segar. Artinya, tenaga kerja pemanen dalam mengerjakan pekerjaannya memanen kelapa sawit akan menentukan kualitas tandan buah segar yang dihasilkan (Nainggolan, 2012). Hasil ini juga menerima pendapat Krisdianto (2017) bahwa optimasi kualitas tandan buah segar kelapa sawit ditentukan dalam proses panen yang dilakukan tenaga kerja pemanen kelapa sawit

\section{Simpulan dan Saran}

\section{Simpulan}

Produktivitas tenaga kerja pemanen kelapa sawit di PT. Perkebunan Nusantara III (Persero) Medan berada dalam kategori sedang. Pemanen dapat memperoleh hasil panen sebanyak 1700-2300 kilogram per hari kerja dengan persentase sebesar 57,32 persen. Faktor internal dan faktor eksternal berpengaruh signifikan terhadap produktivitas tenaga kerja pemanen kelapa sawit di PT. Perkebunan Nusantara III (Persero) Medan. Untuk faktor internal, variabel motivasi kerja memiliki nilai loading yang paling besar. Sedangkan pada faktor eksternal, nilai loading paling besar adalah variabel kesempatan berprestasi.

Faktor internal dan faktor eksternal berpengaruh signifikan terhadap produktivitas tenaga kerja pemanen kelapa sawit. Produktivitas tenaga kerja pemanen kelapa sawit di PT. Perkebunan Nusantara III (Persero) Medan berpengaruh signifikan terhadap kualitas tandan buah segar. Hal tersebut disebabkan karena hasil panen tandan buah segar ditentukan oleh bagaimana produktivitas tenaga kerja pemanen itu sendiri sehingga akan berdampak lamgsung terhadap kualitas baik atau tidaknya hasil panen tandan buah segar kelapa sawit yang diperoleh.

\section{Saran}

Produktivitas tenaga kerja pemanen kelapa sawit di PT. Perkebunan Nusantara III (Persero) Medan berada dalam kategori sedang, tetapi ada kecenderungan mendekati kategori rendah sehingga masih perlu untuk ditingkatkan kembali agak produktivitas tenaga kerja pemanen kelapa sawit dapa sawit dapat lebih tinggi dan mencapai atau bahkan melebihi basis tugas yang ditetapkan perusahan.

Tenaga kerja pemanen kelapa sawit di PT. Perkebunan Nusantara III (Persero) dapat menyeimbangkan segala faktor internal dan eksternal baik dari dalam diri sendiri maupun dari lingkungan luar agar dapat memotivasi diri bekerja semaksimal mungkin sehingga menghasilkan kualitas hasil panen tandan buah segar yang baik sesuai ketentuan pabrik kelapa sawit.

Diperlukan penelitian lanjutan terkait produktivitas tenaga kerja pemanen kelapa sawit untuk memanen tandan buah segar kelapa sawit dengan perolehan hasil kualitas terbaik sesuai grade pabrik guna mengurangi denda terhadap pemanen akibat kesalahan kerja serta meningkatkan mutu hasil panen.

\section{Daftar Pustaka}

Afifah, Septi Nur dan Iskandar Lubis. 2016. Faktor Penentu Produktivitas Tenaga Kerja Panen Kelapa Sawit, Kalimantan Timur. Bul. Agrohorti \$(2): 215-223 (2016). Institut Pertanian Bogor, Bogor.

Badan Pusat Statistik. 2017. Data Kondisi Industri Kelapa Sawit Indonesia dan Malaysia Periode 2006-2015

Ghozali, Imam. 2014. Structural Equation Modelling, Metode Alternatif dengan Partial Least Square (PLS) Edisi 4. 
Badan Penerbit Universitas

Diponogoro. Semarang.

Ismail, Azman, Siti Marshani Ahmad, dkk. 2015. Labour Productivity in the Malaysian Oil Palm Plantation Sector. Oil Palm Industry Economic Journal Vol. 15 (2) September 2015. Persiaran Institusi. Selangor Malaysia.

Jelsama, Idsert, G.C. Schonevek, dkk. 2017. Unpacking Indonesia's Independent Oil Palm Smallholders: An - Actors Disagreegated Appoach to Identifying Environmental and Social Performance Challenges. Land Use Policy 69 (2017) 281-297. Utrecht University. Kenya. ELSEVIER.

Nainggolan, Ronika dan Agus Purwoko. 2012. Faktor-faktor yang Mempengaruhi Produktivitas Tenaga Kerja Pemanen Sawit pada PT. Bio Nysantara Teknologi Bengkulu. ISSN: 1412-8837 Jurnal AGRISEP Vol. 11 No. 1, Maret 2012, Hal: 35-42. Universitas Bengkulu. Bengkulu.

Simamora, Adiguna dkk. 2016. Produktivitas Tenaga Kerja Pemanen di PT. Perkebunan Nusantara VII Unit Kebun Kelapa Sawit Rejosari. Volume 4, No. 2, Mei 2016. Universitas Lampung. Bandar Lampung 